\title{
Accepting the Torch
}

\author{
Stephen Shalansky
}

$\mathrm{I}_{\text {n }}^{\mathrm{n}}$ n the March-April 2016 issue of the Canadian Journal of Hospital Pharmacy (CJHP), Dr Mary Ensom announced that she was stepping down from her role as Editor and was "passing

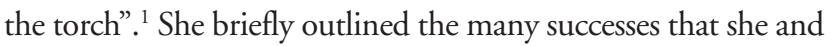
the Journal enjoyed during her 10 years at the helm. Around the same time, I was approached by Peter Zed, the Interim Editor, who asked whether I would consider taking on the role. I did not have to think long about this opportunity, although I was admittedly intimidated by the idea of filling Mary's shoes.

It is a true privilege to again be involved in the publication of our Journal (I am a past Associate Editor). I use the phrase "our Journal" because I see the readers, authors, editors, and reviewers of $C J H P$ as a close-knit community with many professional similarities, despite the incredible geographic range and backgrounds of these individuals. The impact that $C J H P$ has had on our profession and the tremendous expertise of the editorial team compelled me to take up this challenge.

And what a team it is! We should all appreciate the impressive range of international perspectives that the CJHP editorial team represents. Over the past few years, this team has grown to include prominent researchers from countries across the globe, with the current Associate Editors representing Canada, the United States, Scotland, and Australia. Together, this team has expanded the Journal's resources and facilitated the publication of a wider variety of manuscripts. Although the Journal continues to focus on articles describing Canadian hospital pharmacists' involvement in patient care, its mandate has broadened to include submissions that are educational to pharmacists in other collaborative health care settings and other countries. For example, the ongoing $C J H P$ series on international health systems describes the role of pharmacists around the world, allowing Canadian and international pharmacists to learn about innovations that may be of value to their own practices.

I am very proud to be a part of the Journal's continued success and promise to work diligently to sustain its progress. I take this responsibility seriously, because I sincerely believe that $C J H P$ has had a positive impact on many pharmacists' careers and the patient care they provide. The Journal's Editorial Board will make every effort to continue publishing information that helps you, the readers, to provide the highest level of

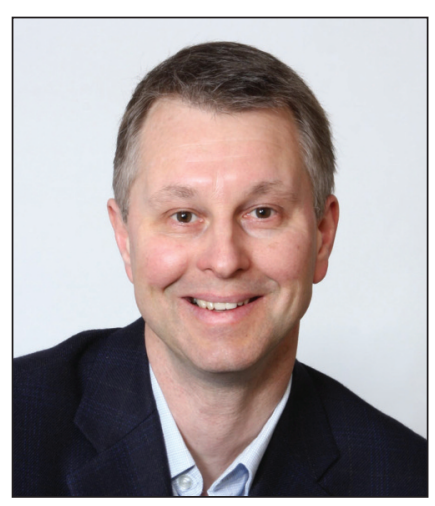
patient care possible, and we will also strive to find innovative ways to disseminate new information valuable to the growth of our profession. We can only accomplish that goal through your continued readership, feedback, and submissions. I look forward to working with you as I accept the torch from Mary and carry it forward along the path of CJHP's continued success.

\section{Reference}

1. Ensom MHH. Paving the way and passing the torch. Can J Hosp Pharm. 2016;69(2):105.

Stephen Shalansky, PharmD, ACPR, FCSHP, is the Clinical Coordinator of the Pharmacy Department, Providence Health Care, and is a Clinical Professor in the Faculty of Pharmaceutical Sciences, University of British Columbia, Vancouver, British Columbia. He is also the Editor of the Canadian Journal of Hospital Pharmacy.

Competing interests: None declared.

\section{Address correspondence to:}

Dr Stephen Shalansky

Pharmacy Department

Providence Health Care

1081 Burrard Street

Vancouver BC V6Z1Y6

e-mail: sshalansky@providencehealth.bc.ca 